Revista Brasileira de Agricultura Irrigada v.12, nº.3, p. 2579 - 2591, 2018

ISSN 1982-7679 (On-line)

Fortaleza, CE, INOVAGRI - http://www.inovagri.org.br

DOI: $10.7127 /$ rbai.v12n300698

Protocolo 698.18 - 11/06/2017 Aprovado em 07/04/2018

\title{
CRESCIMENTO E PIGMENTOS CLOROPLASTÍDICOS DE GENÓTIPOS DE FEIJÃO VIGNA SOB DÉFICIT HÍDRICO
}

\author{
Alberto Soares de Melo ${ }^{1}$, Allisson Rafael Ferreira da Silva ${ }^{2}$, Alexson Filgueiras Dutra ${ }^{3}$, Wellison \\ Filgueiras Dutra ${ }^{4}$, Francisco Vanies da Silva Sá ${ }^{5 *}$, Maurisrael de Moura Rocha ${ }^{6}$
}

\section{RESUMO}

Objetivou-se com este trabalho avaliar o crescimento, o acúmulo de massa seca e o teor de pigmentos cloroplastídicos em genótipos de feijão Vigna sob níveis de reposição da irrigação deficitária. A pesquisa foi realizada, em uma área com solo caracterizado como Neossolo Flúvico, no município de Catolé do Rocha - PB, Brasil. O experimento foi constituído por um estudo de três genótipos de feijão Vigna $\left(\mathrm{G}_{1}=\right.$ BRS Aracé, $\mathrm{G}_{2}=\mathrm{BR} 17$ Gurgueia e $\mathrm{G}_{3}=\mathrm{BRS}$ Marataoã) e quatro lâminas de irrigação (40, 60, 80 e 100\% da ETc), que ao combinados resulta em um fatorial $3 \times 4$, organizado no delineamento em blocos casualizados com quatro repetições. Durante a condução do experimento as plantas foram avaliadas quanto a área foliar, os teores de clorofila a, b e carotenoides, e quanto ao acúmulo de massa seca na folha, caule e total. A irrigação no feijão Vigna, para a região de estudo, pode ser programada em $80 \%$ da evapotranspiração da cultura. O genótipo 'BRS Marataoã' obteve o maior crescimento, acúmulo de massa seca e teores de pigmentos cloroplastídicos, destacando-se como mais tolerante ao estresse hídrico que o 'BRS Aracé' e o 'BR 17 Gurgueia'. O genótipo 'BRS Aracé' obteve os piores índices de crescimento, acúmulo de massa seca e os menores teores de carotenoides sob condições de déficit hídrico, sendo o mais sensível entre os genótipos 'BRS Marataoã’ e ‘BR 17 Gurgueia’.

Palavras-chave: Vigna unguiculata, reposição hídrica, fitomassa.

\footnotetext{
${ }^{1}$ Eng. Agrônomo, Doutor em Recursos Naturais, Professor, Universidade Estadual da Paraíba, Campus I, Campina Grande-PB. E-mail: alberto@uepb.edu.br;

${ }^{2}$ Licenciado em Ciências Agrárias, Mestre em Ciências Agrárias, Universidade Estadual da Paraíba, Campus I, Campina Grande-PB. E-mail: engallisson.rafael@hotmail.com;

${ }^{3}$ Licenciado em Ciências Agrárias, Doutor em Agronomia, Universidade Estadual Paulista, Campus Jaboticabal, Jaboticabal-SP. E-mail: alexsondutra@gmail.com;

${ }^{4}$ Licenciado em Ciências Agrárias, Doutorando em Agronomia, Universidade Federal da Paraíba, Campus II, Areia-PB. E-mail: wellison_eu@hotmail.com;

5 Eng. Agrônomo, Doutor em Engenharia Agrícola, Bolsista de Pós-Doutorado Junior-CNPq, Universidade Federal Rural do Semi-Árido, Campus Mossoró, Mossoró-RN. E-mail: vanies_agronomia@hotmail.com;

${ }^{6}$ Eng. Agrônomo, Doutor em Genética e Melhoramento de Plantas, Empresa Brasileira de Pesquisa Agropecuária, Pesquisa Agropecuária do Meio-Norte, Teresina-PI. E-mail: maurisrael.rocha@embrapa.br
} 


\section{GROWTH AND CHLOROPLASTIDIC PIGMENTS OF GENOTYPES OF VIGNA BEAN UNDER WATER DEFICIT ABSTRACT}

The objective of this work was to evaluate the growth, accumulation of dry mass and chloroplastidic pigment content in Vigna bean genotypes under replacement irrigation levels. The research was carried out, in an area with soil characterized as Neosol Flúvico, in the municipality of Catolé do Rocha - PB, Brazil. The experiment consisted of a study of three genotypes of Vigna beans $\left(\mathrm{G}_{1}=\right.$ BRS Aracé, $\mathrm{G}_{2}=$ BR 17 Gurgueia and $\mathrm{G}_{3}=$ BRS Marataoã) and four irrigation slides (40,60, 80 and 100\% ETc), combined results in a 3 x 4 factorial, organized in a randomized block design with four replicates. During the conduction of the experiment, the plants were evaluated for leaf area, chlorophyll a, b and carotenoids, and for the accumulation of dry mass in leaf, stem and total. Irrigation in Vigna beans, for the study region, can be programmed in $80 \%$ of crop evapotranspiration. The 'BRS Marataoã' genotype showed the highest growth, accumulation of dry mass and chloroplastidic pigment contents, standing out as more tolerant to water stress than 'BRS Aracé' and 'BR 17 Gurgueia'. The genotype 'BRS Aracé' had the worst growth rates, dry mass accumulation and the lowest carotenoid contents under water deficit conditions, being the most sensitive among 'BRS Marataoã' and 'BR 17 Gurgueia' genotypes.

Keywords: Vigna unguiculata, water replenishment, phytomass.

\section{INTRODUÇÃO}

O feijão Vigna, também denominado feijão macaçar, feijão de corda, feijão macassar ou feijão Vigna é uma dicotiledônea pertencente à família Fabace, (ONOFRE, 2008). Esta espécie destaca-se como uma das mais cultivadas na região Nordeste, sendo considerada a principal cultura de subsistência dos agricultores de base familiar da zona rural. Entretanto, os rendimentos obtidos com seu cultivo ainda são extremamente baixos, sendo inferiores a $779 \mathrm{~kg} \mathrm{ha}^{-1}$ (IBGE, 2013).

A baixa produção do feijão Vigna está relacionada à alta sensibilidade do feijoeiro ao déficit hídrico no solo, aliada às incertezas climáticas, principalmente as relacionadas às variações pluviais entre anos e locais de cultivo determinam esses baixos rendimentos e a oscilação da produção anual desta cultura (MOUSINHO et al., 2008; FIGUEIREDO et al., 2008; FERRAZ et al., 2011).

Com o estresse ocorre uma defasagem entre os processos de transpiração, absorção e disponibilidade de água no solo e com isso, temse um desvio significativo das condições ótimas, e induz mudanças e respostas em todos os níveis funcionais do organismo, os quais são reversíveis em princípio, mas podem se tornar permanente (LARCHER, 2000). É um fator externo que exerce uma influência desvantajosa para a planta (TAIZ; ZEIGER, 2013).

Desta forma, a irrigação é uma prática necessária para que os riscos sejam eliminados ou minimizados, suprindo as quantidades de água necessárias para o adequado crescimento e desenvolvimento das plantas (MOUSINHO et al., 2008). No entanto, as ocasiões onde à falta de água é o principal empecilho para realização da irrigação, sendo necessário lançar mão de outras estratégias, como a utilização de variedades e/ou cultivares mais tolerantes (PAVANI et al., 2009; NASCIMENTO et al., 2011).

O desenvolvimento de cultivares mais tolerantes a períodos de deficiência hídrica no solo, tal como o desenvolvimento de mecanismos que auxiliem as plantas a tolerar períodos prolongados de seca será essencial na manutenção da produção agrícola brasileira e mundial (NEPOMUCENO et al., 2001). As diferentes reações de cada genótipo a essas variações permitem que ele possa tolerá-las quando em níveis críticos, mantendo, ainda assim, taxas adequadas de fotossíntese (RIBEIRO et al., 2004; DUTRA et al., 2015). 
Cultivares de feijão Vigna apresentam diferentes respostas fisiológicas quando submetidos a déficit de água no solo (DUTRA et al., 2015; MOREIRA et al., 2016).

Com isso, objetivou-se avaliar o crescimento, a fitomassa e os pigmentos cloroplastídicos de genótipos de feijão Vigna sob níveis de reposição da irrigação deficitária.

\section{MATERIAL E MÉTODOS}

A pesquisa foi realizada na área experimental do Setor de Fruticultura e Ecofisiologia Vegetal pertencente ao Centro de Ciências Humanas e Agrárias (CCHA), Campus IV da Universidade Estadual da Paraíba (UEPB), localizado no município de Catolé do Rocha, PB. No período de 19 de setembro a 12 de dezembro de 2012. Esse período corresponde ao tempo de estiagem nessa região, sendo necessário o uso de irrigação nos cultivos.

A cidade está situada a $6^{\circ} 21^{\prime}$ de latitude $S$ e $37^{\circ} 48^{\prime}$ de longitude $\mathrm{O}$, a uma altitude de 250 m. O clima da região é do tipo BSw'h', segundo classificação de Köppen, caracterizando-se por ser semiárido quente, com duas estações distintas, uma chuvosa com precipitação irregular e outra sem precipitação. A precipitação média anual é de $870 \mathrm{~mm}$, temperatura média de $27{ }^{\circ} \mathrm{C}$ com período chuvoso concentrando-se entre os meses de fevereiro e abril, máximas de $35{ }^{\circ} \mathrm{C}$ e mínimas de $19{ }^{\circ} \mathrm{C}$.

O experimento foi constituído de três genótipos de feijão Vigna, obtidos no programa de melhoramento genético de feijão da Embrapa Meio Norte com potencial de produção no semiárido $\left(\mathrm{G}_{1}=\mathrm{BRS}\right.$ Aracé, $\mathrm{G}_{2}=\mathrm{BR} 17$ Gurgueia e $\mathrm{G}_{3}=$ BRS Marataoã) e quatro lâminas de irrigação (40, 60, 80 e 100\% da ETc). Combinado em esquema fatorial $3 \times 4$, organizado em delineamento de blocos casualizados, com quatro repetições e dez plantas por repetição.

O experimento envolveu três genótipos de feijão Vigna, sendo eles: BRS Aracé, BR 17 Gurguéia e BRS Marataoã. Na tabela 1, estão descritas as principais características dos genótipos de feijão.

Tabela 1. Características das cultivares de feijão Vigna.

\begin{tabular}{|c|c|c|c|}
\hline \multirow{2}{*}{ Características } & \multicolumn{3}{|c|}{ Cultivares } \\
\hline & BRS Aracé & BR 17 Gurguéia & BRS Marataoã \\
\hline Hábito de Crescimento & Indeterminado & Indeterminado & Indeterminado \\
\hline Porte & Semiprostado & Enramador & Semiprostado \\
\hline $\mathrm{N}^{\mathrm{o}}$ de dias para floração & 41 & 43 & 42 \\
\hline Cor da vagem imatura & Verde & Verde & Verde clara \\
\hline Cor vagem seca & Roxa & Amarela & Roxa \\
\hline Comprimento médio da vagem & $20 \mathrm{~cm}$ & $17 \mathrm{~cm}$ & $18 \mathrm{~cm}$ \\
\hline Nº médio de grãos por vagem & 15 & 15 & 15 \\
\hline Ciclo & 70 a 75 dias & 75 dias & 70 a 75 dias \\
\hline Peso médio de 100 sementes & $18 g$ & $12,5 \mathrm{~g}$ & $15,5 \mathrm{~g}$ \\
\hline Produtividade média & $985 \mathrm{~kg}$ & $1694 \mathrm{~kg}$ & $1807 \mathrm{~kg}$ \\
\hline
\end{tabular}

$\mathrm{Na}$ localidade, as condições edáficas foram representadas por um solo classificado como Neossolo Flúvico Tb Eutrófico típico, com textura arenosa (SANTOS et al., 2013), em que amostras de solo foram coletadas para análise de suas características físicas-hídricas e químicas (Tabela 2). O preparo do solo foi realizado por uma aração com revolvimento do solo a uma profundidade de $0,20 \mathrm{~m} \mathrm{e}$, em seguida, fez-se o nivelamento com grade niveladora. As adubações foram feitas de acordo com os resultados da análise de solo ilustrados na Tabela 2, direcionada para a cultura do feijão Vigna. A adubação foi comum a todos os tratamentos utilizando adubos minerais com NPK (Nitrogênio, Fósforo e Potássio), na forma de Ureia (45\% de N), superfosfato simples (22\% de $\mathrm{P}_{2} \mathrm{O}_{5}$ ) e cloreto de potássio $\left(60 \%\right.$ de $\left.\mathrm{K}_{2} \mathrm{O}\right)$, seguindo a recomendação para o cultivo do 
feijão Vigna do estado do Pernambuco, sendo 20, 60 e $60 \mathrm{~kg} \mathrm{ha}^{-1}$, de nitrogênio, fósforo e potássio, respectivamente (CAVALCANTE, 2008).

Tabela 2. Valores da análise físico-hídrica e química do solo na profundidade de 0-20 cm da área experimental.

\begin{tabular}{lclc}
\hline Atributos físico-hídricas & Resultado & \multicolumn{1}{c}{ Características químicas } & Resultado \\
\hline Granulométrica $\left(\mathrm{g} \mathrm{kg}^{-1}\right)$ & & Cálcio $\left(\mathrm{Ca}^{+2}\right)\left(\mathrm{cmol}_{\mathrm{c}} \mathrm{dm}^{-3}\right)$ & 4,8 \\
Areia & $773,7(1)$ & Sódio $\left(\mathrm{Na}^{+}\right)\left(\mathrm{cmol}_{\mathrm{c}} \mathrm{dm}^{-3}\right)$ & 0,404 \\
Silte & 168,3 & Magnésio $\left(\mathrm{Mg}^{+2}\right)\left(\mathrm{cmol}_{\mathrm{c}} \mathrm{dm}^{-3}\right)$ & 1,55 \\
Argila & 58 & Potássio $\left(\mathrm{K}^{+}\right)\left(\mathrm{mg} \mathrm{dm}^{-3}\right)$ & 309,08 \\
Classificação textural & Franco-arenoso & Fósforo $(\mathrm{P})\left(\mathrm{mg} \mathrm{dm}^{-3}\right)$ & 186,97 \\
Densidade $\left(\mathrm{g} \mathrm{cm}^{-3}\right)$ & & Matéria orgânica M.O. $\left(\mathrm{g} \mathrm{Kg}^{-1}\right)$ & 12,62 \\
Solo & 1,53 & $\mathrm{pH} \mathrm{H} \mathrm{H}_{2} \mathrm{O}(1: 2,5)$ & 7,32 \\
Partículas & 2,65 & Soma de bases $(\mathrm{SB})\left(\mathrm{cmol}_{\mathrm{c}} \mathrm{dm}^{-3}\right)$ & 7,54 \\
Porosidade total (\%) & 42,26 & Hidrogênio $+\mathrm{Aluminio}\left(\mathrm{cmol}_{\mathrm{c}} \mathrm{dm}^{3}\right)$ & 0,413 \\
Umidade $\left(\mathrm{g} \mathrm{kg}^{-1}\right)$ & & Aluminio $\left(\mathrm{AL}^{+3}\right)\left(\mathrm{cmol}_{\mathrm{C}} \mathrm{dm}^{3}\right)$ & 0,0 \\
Capacidade de campo & 114,4 & CTC $\left(\mathrm{cmol}_{\mathrm{c}} \mathrm{dm}^{3}\right)$ & 7,96 \\
Ponto de murcha permanente & 35,1 & & \\
Água disponível (\% de peso) & 7,93 & & \\
(1) & &
\end{tabular}

O manejo da irrigação foi em função da evapotranspiração da cultura (ETc), determinado a partir da evapotranspiração de referência (ETo) pelo método de PenmanMonteith (ALLEN et al., 1998), e o Kc proposto por Doorenbos e Kassan (1979) nas diferentes fases de desenvolvimento da cultura: germinação - folhas primárias (V0 - V2), Kc de 0,30 à 0,40 ; primeira folha trifoliada - terceira folha trifoliada (V3 - V4), Kc de 0,70 à 0,80; pré-floração - formação de vagens (R5 - R7), Kc de 1,05 a 1,20; enchimento de grãos (R8) e maturação (R9), Kc de 0,25 à 0,30, onde a partir daí foi calculado a lâmina bruta, cálculo da intensidade de aplicação e o cálculo do tempo de irrigação para o sistema de irrigação localizada, utilizando gotejadores autocompensantes, com vazão média de $4 \mathrm{~L} \mathrm{~h}^{-1}$.

A área foliar (AF) $\left(\mathrm{cm}^{2}\right)$ de cada planta analisada semanalmente foi estimada por meio da leitura do comprimento e largura de cada folha utilizando uma régua graduada em centímetros
(Figura 4A), onde para obter a AF por planta utilizou-se a equação (Eq. 1) proposta por Queiroga et al. (2003).

$$
A F T=0,1026 \times L f^{1,6871}
$$

Em que:

$\mathrm{Lf}=$ a largura de cada folíolo $(\mathrm{cm})$.

Imediatamente após as determinações da área foliar, foram coletadas amostras foliares na parte central do limbo e, posteriormente, levadas ao Laboratório de Ecofisiologia para quantificação dos teores de clorofila total, $a$ e $b$ ( $\mu \mathrm{g} \mathrm{cm}^{-2}$ ) conforme método laboratorial desenvolvido por Lichthenthaler (1987), por meio de amostras de 5 discos do limbo da $3^{\text {a }}$ folha madura a partir do ápice. A partir dos extratos, foi determinada a concentração de clorofila nas soluções utilizando um espectofotômetro no comprimento de onda de absorbância (470, 646,8 e 663,2nm) com base nas Eq. 2, 3 e 4 descritas abaixo:

$$
\begin{aligned}
& \text { Clo } a=12,25 A B S_{663,2}-2,79 A B S_{646,8} \\
& \text { Clo } b=21,50 A B S_{646,8}-5,10 A B S_{663,2}
\end{aligned}
$$

$$
\text { Cart totais }=\left(1000 A B S_{470}-1,82 \text { clo } a-85,02 \text { clo } b\right) / 198
$$


Em que:

ABS = absorbância;

Clo = clorofila; $\mathrm{e}$

Cart $=$ Carotenóides.

Em cada análise de área foliar, em intervalos de sete dias, uma planta foi retirada do campo e em seguida separou-se as folhas do caule e ramos. Posteriormente, o material foi colocado em estufa de circulação de ar, sendo que após 72 horas, posteriormente o material foi pesado em balança de precisão para obter a massa seca do caule (MSC), massa seca da folha (MSF) e a massa seca total (MST).

Os dados das variáveis de crescimento, teores de pigmentos cloroplastídicos e de acúmulo de matéria seca, foram submetidos à análise de variância pelo teste $\mathrm{F}(\mathrm{P} \leq 5 \%)$. Os modelos de regressão foram ajustados de acordo com o coeficiente de determinação $(\alpha \leq 5 \%)$ em caso de significância das lâminas de irrigação ou da interação delas com as cultivares de feijão Vigna. Em caso de efeito significativo isolado das cultivares de feijão Vigna, as médias foram comparadas pelo teste de Tukey $(\alpha \leq 5 \%)$, utilizando o programa SAEG 9.1.

\section{RESULTADOS E DISCUSSÃO}

Houve efeito significativo da aplicação das lâminas de irrigação ( $p<0,05)$ nos genótipos de feijão Vigna quando avaliou-se a massa seca do caule (MSC), massa seca das folhas (MSF) e massa seca total (MST) e área foliar (AF), indicando que os níveis de deficiência hídrica aplicados no solo, influenciaram significativamente o desempenho do crescimento e desenvolvimento de plantas de feijão Vigna (Tabela 3). Nota-se, ainda, na Tabela 3 diferença significativa entre os genótipos de feijão Vigna para as variáveis MSF, MSC, MST e AF em todas as datas avaliadas, exceto para massa seca do caule aos 27 dias após semeadura (DAS). Já com relação à interação entre os fatores lâmina e genótipo, observa-se que apenas MSC aos 34 DAS e a área foliar nas duas primeiras avaliações (20 e 27 DAS) não teve efeito significativo $(\mathrm{p} \geq 0,05)$ (Tabela 3$)$.

As diferenças entre os acúmulos de matéria seca e área foliar para as diferentes reposições hídricas tornaram-se claras a partir da terceira coleta, aos 34 DAS (Figuras 1 e 2). Percebe-se com a aplicação das menores lâminas de irrigação, ou seja 40 e 60\% da ETc, proporcionaram aos genótipos de feijão Vigna os menores valores de MSF e MSC dos 34 aos 48 DAS, sendo este comportamento semelhante nos três genótipos de feijão estudados. É importante salientar que a lâmina de irrigação de 80\% da ETc, promoveu crescimento satisfatório os genótipos de feijão Vigna, obtendo-se valores próximos em média as plantas cultivadas com $100 \%$ ETc. Com isso essa lâmina pode ser utilizada para o cultivo desses genótipos, admitindo-se pequenas perdas no crescimento e acúmulo de matéria seca. Avaliando o crescimento e produção de genótipos de feijão Vigna, Dutra et al. (2015) e Moreira et al. (2016), também observaram que lâminas de irrigação inferiores a 80\% da ETc promovem drásticas perdas no rendimento das plantas.

Tabela 3. Resumo das análises de variância para as variáveis massa seca das folhas (MSF), massa seca do caule (MSC), massa seca total (MST) e área foliar (AF) aos 20, 27, 34, 41 e 48 dias após semeadura (DAS) em genótipos de feijão Vigna sob aplicação de lâminas de irrigação.

\begin{tabular}{|c|c|c|c|c|c|c|}
\hline \multirow{2}{*}{ F.V. } & \multirow{2}{*}{ G.L. } & \multicolumn{5}{|c|}{ Quadrados Médios - MSF } \\
\hline & & MSF-20 & MSF-27 & MSF-34 & MSF-41 & MSF-48 \\
\hline Bloco & 3 & $0,02922^{*}$ & $0,0734^{\text {ns }}$ & $0,5714^{\mathrm{ns}}$ & $0,4296^{\text {ns }}$ & $0,1630^{\mathrm{ns}}$ \\
\hline Lâmina (La) & 2 & $0,2773^{*}$ & $0,7336^{*}$ & $9,4769^{*}$ & $19,4366^{*}$ & $161,44^{*}$ \\
\hline Genótipo (Ge) & 3 & $0,1249^{*}$ & $1,1540^{*}$ & $2,0928^{*}$ & $14,1266^{*}$ & $32,4137^{*}$ \\
\hline Ge x La & 6 & $0,0290^{*}$ & $0,1447^{*}$ & $4,5900^{*}$ & $2,0090^{*}$ & $20,5833^{*}$ \\
\hline Resíduo & 33 & 0,0085 & 0,0351 & 0,218 & 5,8171 & 0,8237 \\
\hline C.V. (\%) & & 11,549 & 11,739 & 14,904 & 6,102 & 6,348 \\
\hline \multirow{2}{*}{ F.V. } & \multirow{2}{*}{ G.L. } & \multicolumn{5}{|c|}{ Quadrados Médios - MSC } \\
\hline & & MSC-20 & MSC-27 & MSC-34 & MSC-41 & MSC-48 \\
\hline Bloco & 3 & $0,0007^{\mathrm{ns}}$ & $0,0075^{\mathrm{ns}}$ & $0,0841^{*}$ & $0,0645^{\mathrm{ns}}$ & $0,3760^{\text {ns }}$ \\
\hline Lâmina (La) & 2 & $0,0270^{*}$ & $0,0472^{*}$ & $0,9288^{*}$ & $1,8015^{*}$ & $23,0352^{*}$ \\
\hline
\end{tabular}


Melo et al.

\begin{tabular}{|c|c|c|c|c|c|c|}
\hline Genótipo (Ge) & 3 & $0,0378^{*}$ & $0,0072^{\mathrm{ns}}$ & $0,1206^{*}$ & $3,1753^{*}$ & $9,6210^{*}$ \\
\hline Ge x La & 6 & $0,0051^{*}$ & $0,0110^{*}$ & $0,0367^{\text {ns }}$ & $0,2934^{*}$ & $1,1380^{*}$ \\
\hline Resíduo & 33 & 0,0007 & 0,2955 & 0,0263 & 0,0629 & 0,2113 \\
\hline C.V. (\%) & & 10,073 & 11,892 & 16,013 & 11,409 & 10,908 \\
\hline \multirow{2}{*}{ F.V. } & \multirow{2}{*}{ G.L. } & \multicolumn{5}{|c|}{ Quadrados Médios - MST } \\
\hline & & MST-20 & MST-27 & MST-34 & MST-41 & MST-48 \\
\hline Bloco & 3 & $0,0394^{*}$ & $0,1127^{*}$ & $1,0196^{*}$ & $0,7996^{*}$ & $0,8013^{\mathrm{ns}}$ \\
\hline Lâmina (La) & 2 & $0,4735^{*}$ & $1,1515^{*}$ & $16,1552^{*}$ & $31,9631^{*}$ & $304,1989^{*}$ \\
\hline Genótipo (Ge) & 3 & $0,2528^{*}$ & $1,0012^{*}$ & $1,3610^{*}$ & $18,5336^{*}$ & $71,8779^{*}$ \\
\hline Ge x La & 6 & $0,0570^{*}$ & $0,2195^{*}$ & $4,7038^{*}$ & $2,8148^{*}$ & $28,6996^{*}$ \\
\hline Resíduo & 33 & 0,0113 & 0,0393 & 0,257 & 0,2544 & 1,161 \\
\hline C.V. (\%) & & 9,895 & 9,659 & 12,226 & 5,555 & 5,82 \\
\hline \multirow{2}{*}{ F.V. } & \multirow{2}{*}{ G.L. } & \multicolumn{5}{|c|}{ Quadrados Médios - AF } \\
\hline & & AF-20 & AF-27 & AF-34 & AF-41 & AF-48 \\
\hline Bloco & 3 & $1,5034^{\mathrm{ns}}$ & $3,1242^{\mathrm{ns}}$ & $18,7664^{\mathrm{ns}}$ & $100,95^{\mathrm{ns}}$ & $54,9154^{\text {ns }}$ \\
\hline Lâmina (La) & 2 & $5,8079^{*}$ & $32,7080^{*}$ & $1186,57^{*}$ & $6034,36^{*}$ & $9158,11^{*}$ \\
\hline Genótipo (Ge) & 3 & $7,4693^{*}$ & $58,0001^{*}$ & $730,0764^{*}$ & $4306,53^{*}$ & $852,4038^{*}$ \\
\hline Ge x La & 6 & $0,6137^{\mathrm{ns}}$ & $2,9359^{\mathrm{ns}}$ & $507,9651^{*}$ & $1208,88^{*}$ & $672,6093^{*}$ \\
\hline Resíduo & 33 & 0,5987 & 2,154 & 15,647 & 50,4425 & 70,2959 \\
\hline C.V. (\%) & & 14,333 & 10,601 & 14,816 & 11,497 & 7,143 \\
\hline
\end{tabular}

F.V. - Fontes de Variação; C.V. - Coeficiente de Variação; G.L. - Graus de Liberdade; * Significativo (p<0,05); ${ }^{\text {ns }}$ Não Significativo $(\mathrm{p}>0,05)$.

A

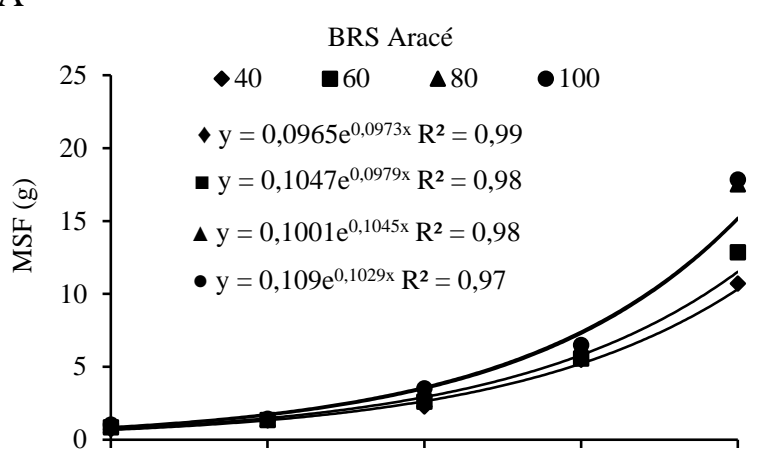

B

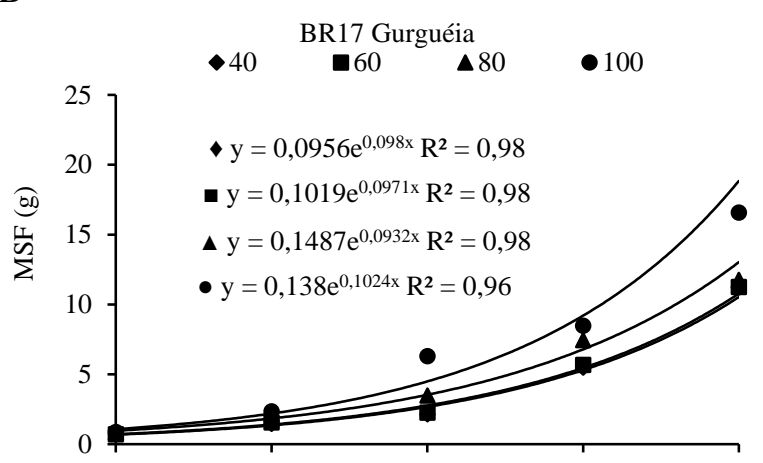

D

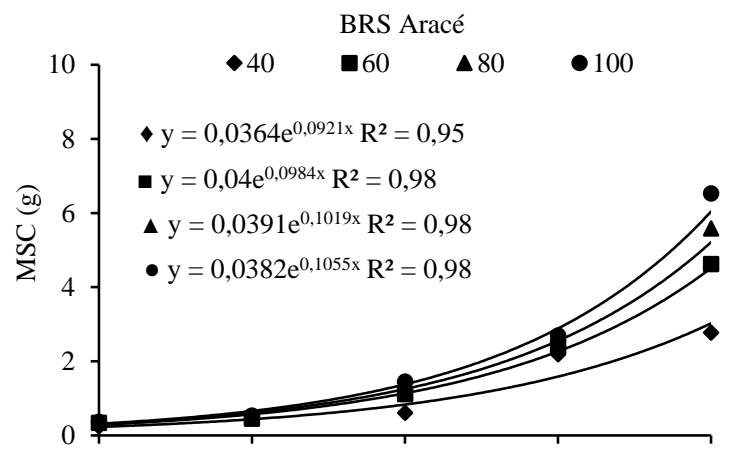

E

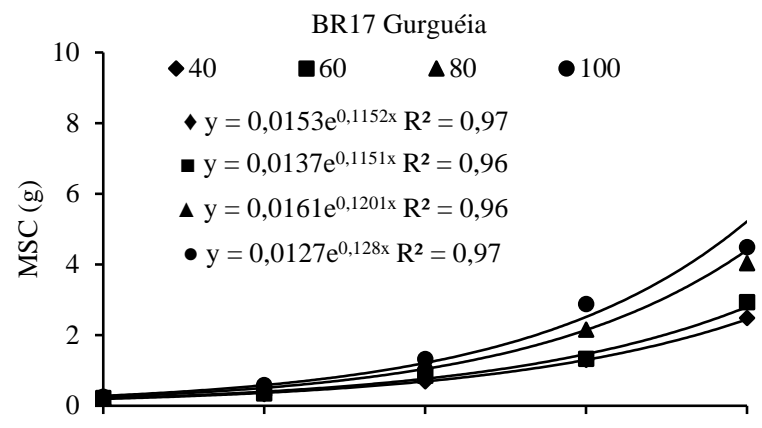


C

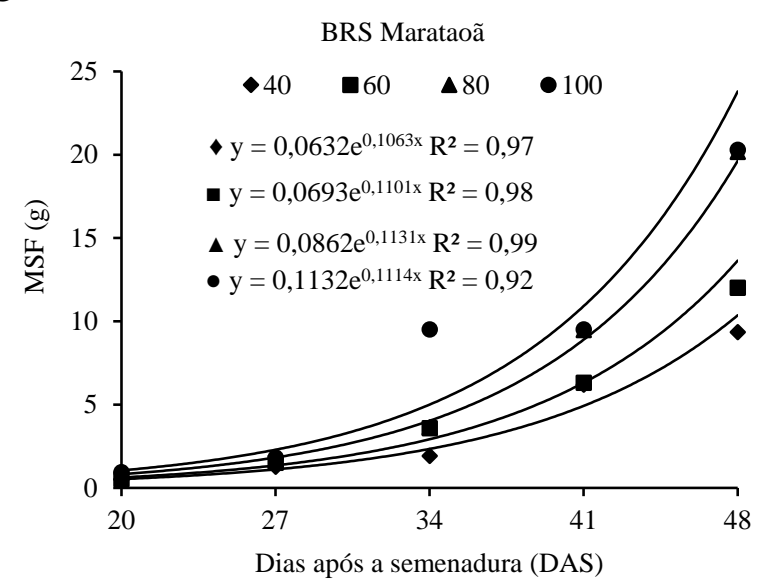

$\mathrm{F}$

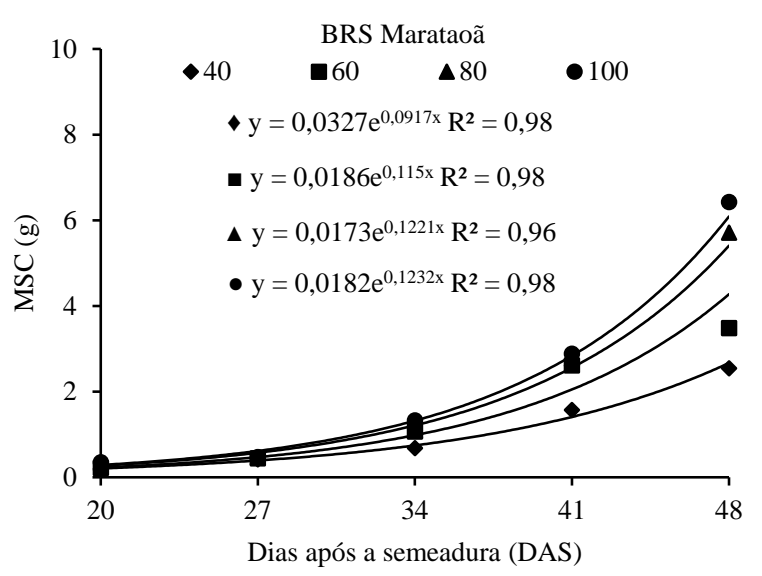

Figura 1. Massa seca das folhas (A, B e C) e do caule (D, E e F) para os genótipos de feijão Vigna 'BRS Aracé', ‘BR17 Gurguéia’ e ‘BRS Marataoã’ para diferentes reposições hídricas (•40, $\bullet 60$, $\mathbf{\Delta} 80$ e •100\% da ETc) em função do tempo após a semeadura (DAS).

A ocorrência de déficit hídrico provoca a diminuição de matéria seca e da área foliar juntamente com a produção, inviabilizando o processo fotossintético, uma vez que a água, além de ser componente básico da reação, também é responsável pela manutenção da transpiração, essencial para a permeabilidade do gás carbônico no mesófilo foliar (BUCHANAN et al., 2000). Alguns autores mencionam que a diminuição na área foliar ocorre devido à redução do tamanho das células do parênquima paliçádico. Esse fenômeno é explicado, pela inibição da expansão celular em condições de estresse hídrico, tendo em vista que à medida que o conteúdo de água na célula diminui, está se contrai e as paredes tornam-se flácidas, assim os solutos ficam cada vez mais concentrados e a membrana plasmática torna-se mais espessa (LARCHER, 2000; TAIZ; ZEIGER 2013).

A área foliar e o acúmulo de massa seca total do feijão Vigna segue a mesma tendência observada para o acúmulo de massa seca do caule e das folhas, sem muita distinção entre as lâminas aplicadas até os primeiros 34 DAS (Figura 2A, B, C, D, E e F). No entanto, com o maior desenvolvimento das plantas verifica-se diferenciação entre as laminas de irrigação a partir do 34 DAS, observando o maiores áreas foliares e acúmulo de massa seca nas plantas irrigada com 80 e $100 \%$ da ETc.

Resultados semelhantes foram observados por Nascimento et al. (2011) e Bastos et al. (2012) avaliando a tolerância do feijão Vigna ao déficit hídrico, os autores constataram que as lâminas de irrigação deficitária afetam drasticamente a área foliar das plantas de feijão Vigna, e que essa redução compromete diretamente a produção de graus das plantas. Esse fenômeno ocorre devido a redução da fotossíntese em função do fechamento estomático, ocasionado pela redução do potencial hídrico do solo, assim o suprimento de carboidratos das plantas é reduzido, muitas vezes sendo suficiente apenas para manter suas atividade vitais (FERRAZ et al., 2011; SOUZA et al., 2016).

Dentre as cultivares de feijão Vigna avaliados, a cultivar 'BRS Marataoã' apresentou com as maiores lâminas os maiores valores de MSF e MST e a maior AF (Figura 1C, 2C e 2F, respectivamente), tendo a cultivar 'BRS Aracé' com o maior valor de MSC (Figura 1D). 
A

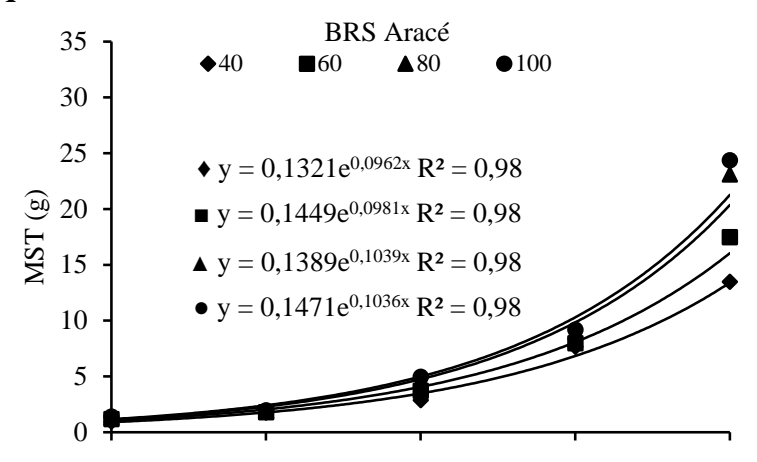

B

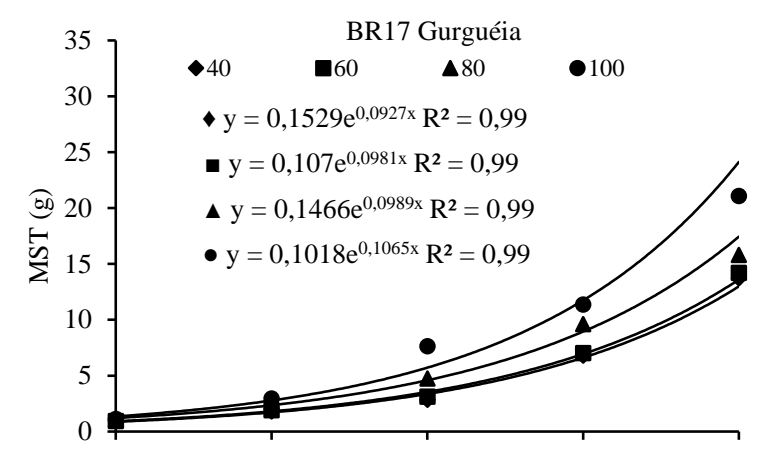

C

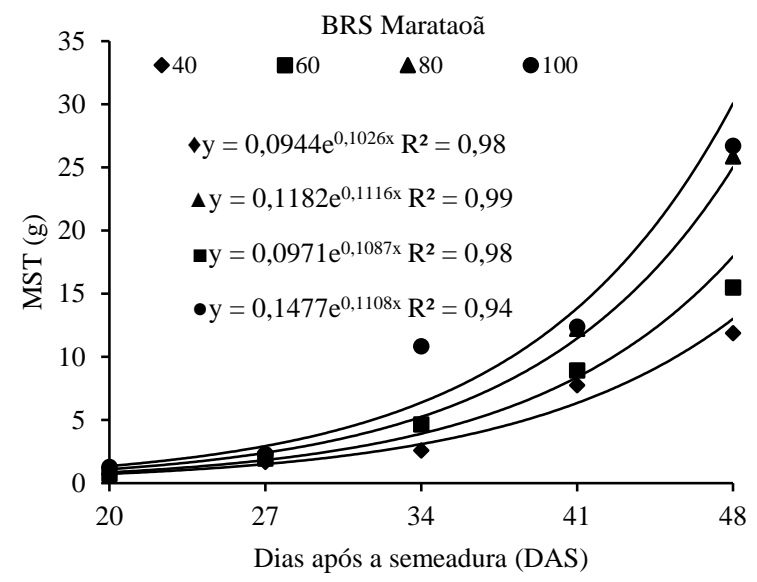

$\mathrm{D}$

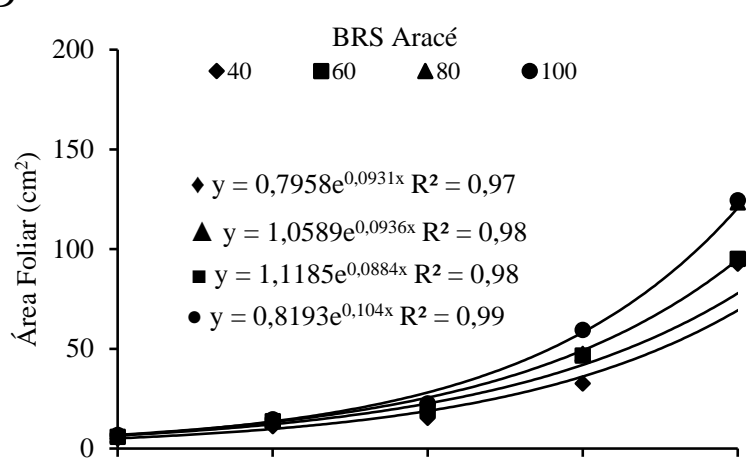

E

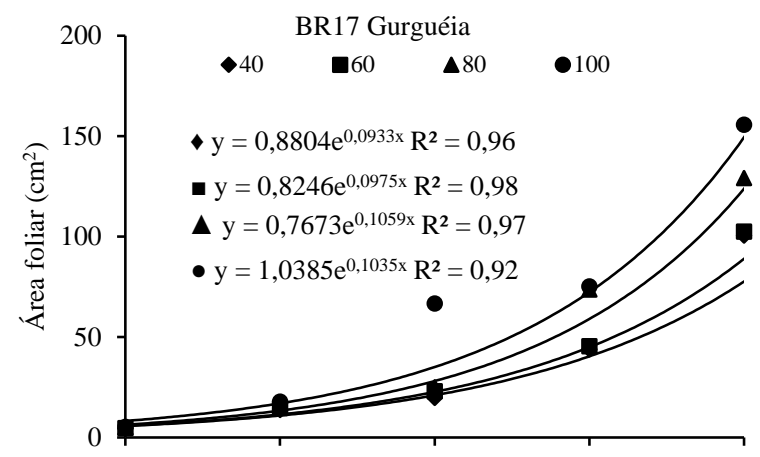

$\mathrm{F}$

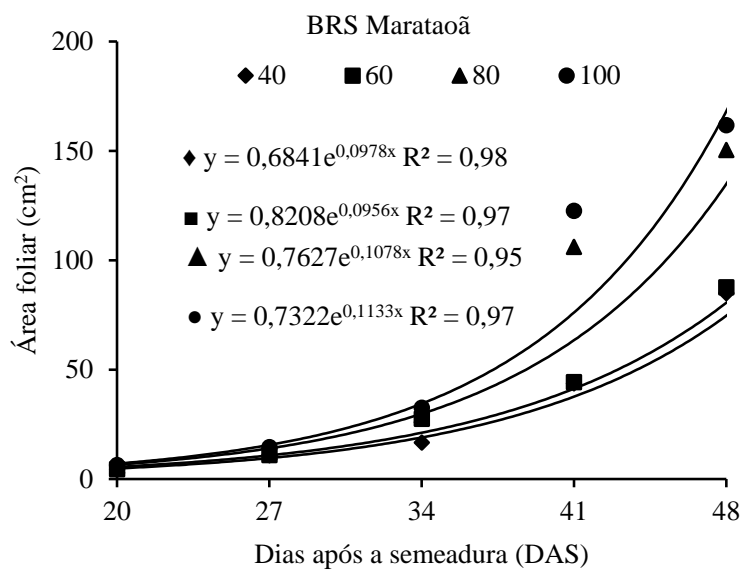

Figura 2. Massa seca total (A, B e C) e área foliar por planta (D, E e F) para os genótipos de feijão Vigna 'BRS Aracé', 'BR17 Gurguéia' e 'BRS Marataoã’ para diferentes reposições hídricas ( $\bullet 40, \boldsymbol{\bullet} 60, \mathbf{\Delta} 80$ e $\bullet 100 \%$ da ETc) em função do tempo após a semeadura (DAS).

O 'BRS Aracé' obteve a menor área foliar e o menor cúmulo de MSF e MST (Figura 1C, 2C e 2F, respectivamente). De acordo com Taiz e Zeiger (2013), a redução na área foliar das plantas ocorre como mecanismo de defesa da planta contra a deficiência hídrica. Dessa forma, com a área foliar menor, a transpiração é reduzida, entretanto ocorre limitação da área fotossinteticamente ativa, afetando negativamente a atividade fotossintética da planta, e consequentemente restringindo o acúmulo de massa seca (DUTRA et al., 2015; MOERIA et al., 2016).

No estudo das variáveis clorofila a, clorofila b e caratenóides os fatores lâminas de irrigação (La) e genótipos de feijão Vigna $(\mathrm{Ge})$ e a interação entre os fatores $\left(\begin{array}{lll}G e & x & L a\end{array}\right)$ influenciaram significativamente nos resultados de todas as variáveis analisadas tanto nas avaliações sob estresse de 24 
horas (E) como nas avaliações após os níveis de irrigação determinados a reidratação $(\mathrm{R})$ das plantas com (Tabela 4).

Tabela 4. Resumo das análises de variância para as variáveis: clorofila A (Clor a), clorofila B (Clor b) e caratenóides (Carat) em folhas de genótipos de feijão Vigna sob estresse de 24 horas e reidratação com diferentes lâminas de irrigação.

\begin{tabular}{lccccccc}
\hline \multirow{2}{*}{ F.V. } & \multirow{2}{*}{ G.L } & \multicolumn{7}{c}{ Quadrados Médios } \\
\cline { 3 - 7 } & & Clor a (E) & Clor a (R) & Clor a (E) & Clor a (R) & Carat (E) & Carot (R) \\
\hline Bloco & 3 & $0,1555^{*}$ & $0,1558^{*}$ & $0,1159^{\text {ns }}$ & $0,1159^{\text {ns }}$ & $0,1369^{*}$ & $0,1371^{\text {ns }}$ \\
Lâmina (La) & 2 & $3,2654^{* *}$ & $3,2646^{* *}$ & $3,3651^{* *}$ & $3,3651^{* *}$ & $3,4392^{* *}$ & $3,4396^{* *}$ \\
Genótipo (Ge) & 3 & $5,5713^{* *}$ & $5,5689^{* *}$ & $5,4314^{* *}$ & $5,4314^{* *}$ & $5,9021^{* *}$ & $5,8978^{* *}$ \\
Ge x La & 6 & $0,5888^{* *}$ & $0,5879^{* *}$ & $0,4907^{* *}$ & $0,4907^{* *}$ & $0,6158^{* *}$ & $0,6155^{* *}$ \\
Resíduo & 33 & 0,0500 & 0,05 & 0,0612 & 0,0612 & 0,0496 & 0,0496 \\
\hline C.V. (\%) & & 5,85 & 5,81 & 12,10 & 11,68 & 12,82 & 12,3
\end{tabular}

F.V. - Fontes de Variação; C.V. - Coeficiente de Variação; G.L. - Graus de Liberdade; **Significativo ( $<0,01$ );

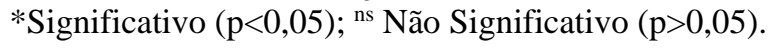

A irrigação deficitária aumentou a síntese de clorofila $a$ e de clorofila $b$ nas folhas dos genótipos de feijão Vigna quando comparado ao nível de $100 \%$ da ETc. Fato este, principalmente observado no genótipo 'BRS Marataoã' com diferenças de 44, 28 e 26\% paras os teores de clorofila a, e de 80,55 e $54 \%$ nos teores de clorofila $b$ em relação ao 'BRS Aracé' nas lâminas deficitárias de 40, 60 e 80\% da ETc, respectivamente (Figura 3). Esse

A

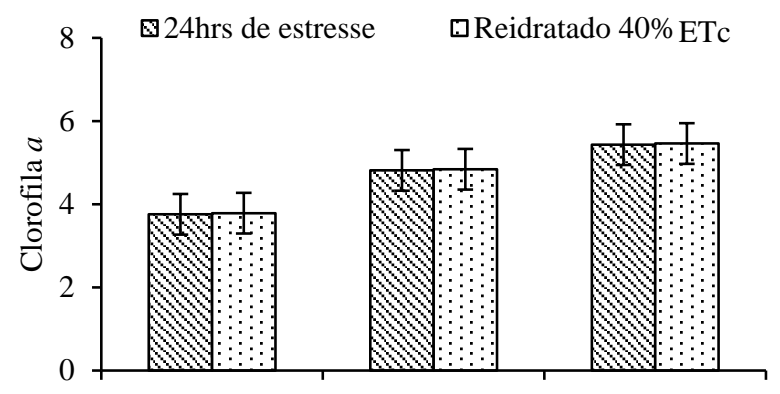

C

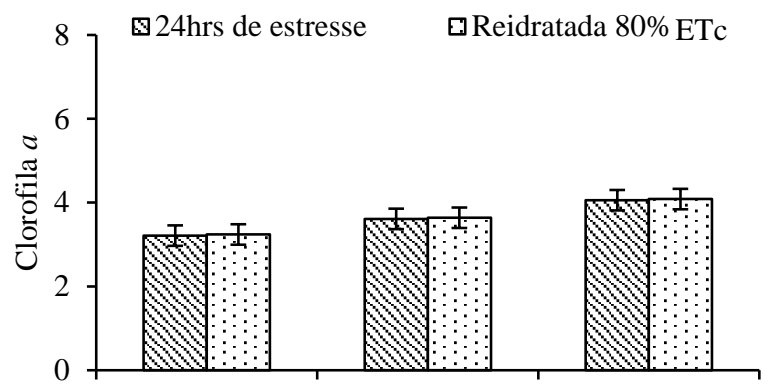

comportamento observado para os teores de clorofila a e b podem ser visto como um mecanismo de tolerância do genótipo a condição de estresse, de modo aumentar a concentração de clorofila na folha, buscado obter uma maior atividade fotossintética, principalmente devido as reduções na área foliar das plantas sobre estresse hídrico (Figura $2 \mathrm{D}, \mathrm{E}$ e F).
B

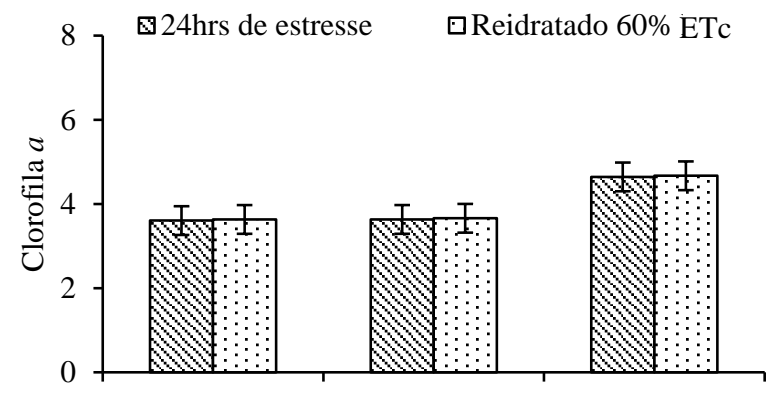

D

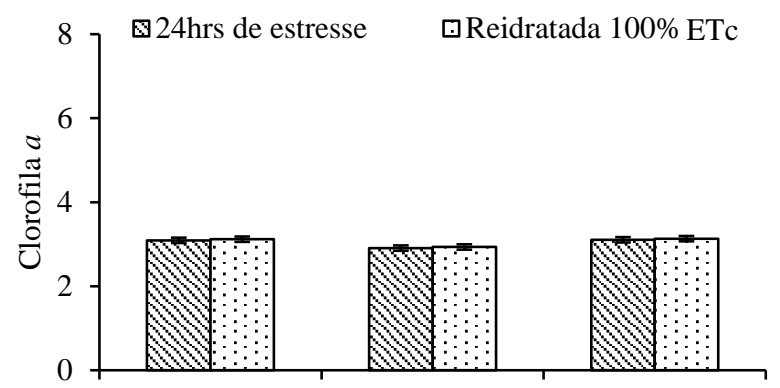


$\mathrm{E}$

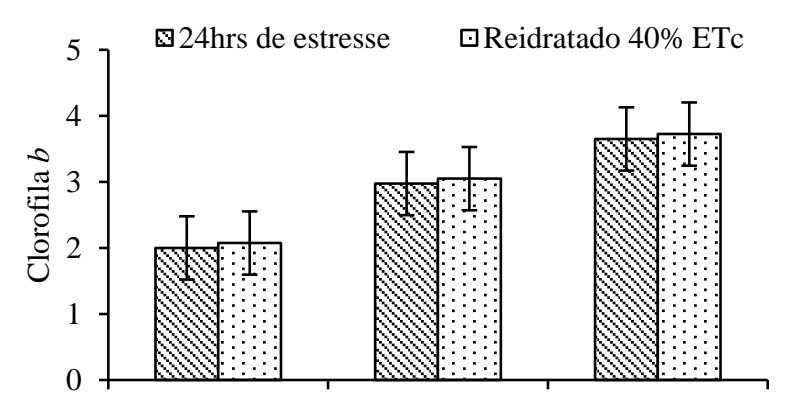

G

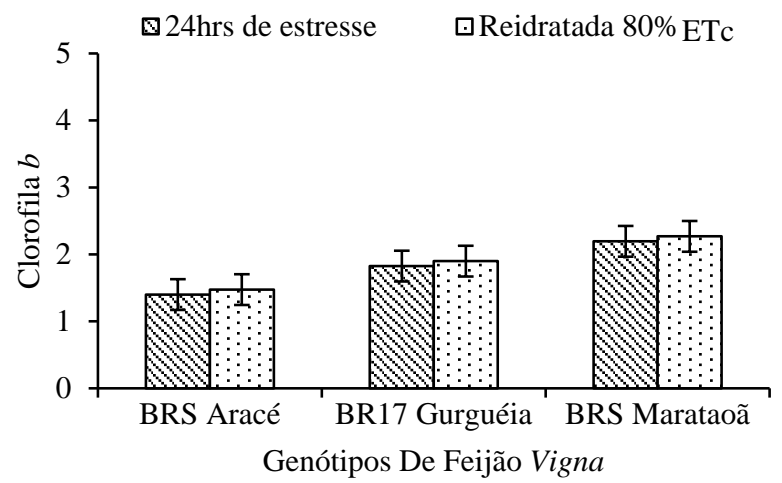

$\mathrm{F}$

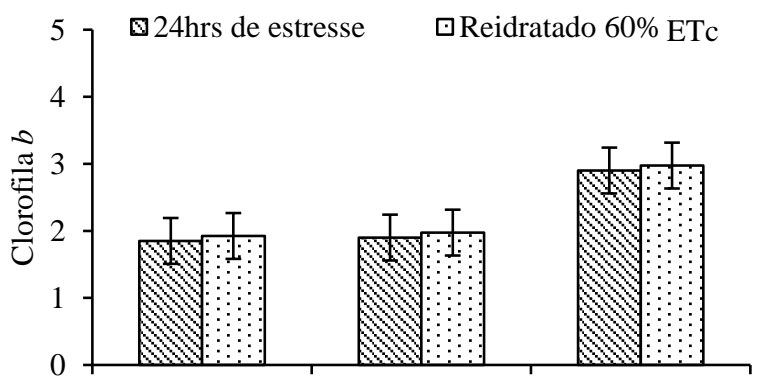

$\mathrm{H}$

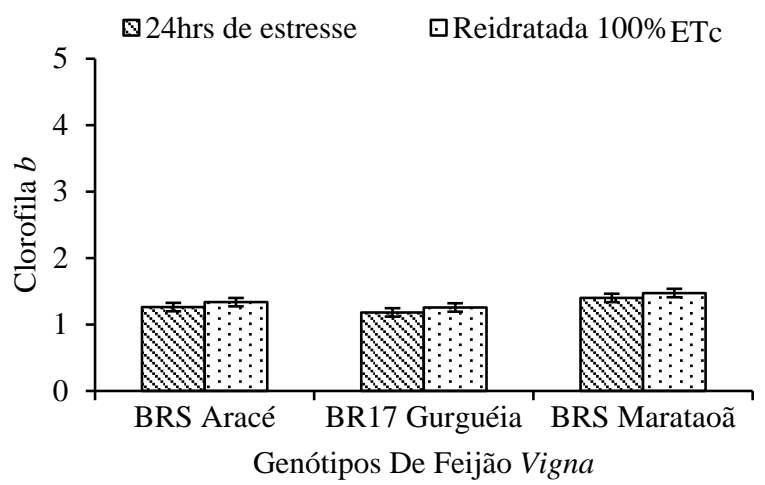

Figura 3. Concentração de clorofila $a\left(\mu \mathrm{g} \mathrm{g}^{-1}\right)$ (A, B, C e D) e de clorofila $b\left(\mu \mathrm{g} \mathrm{g}^{-1}\right)$ (E, F, G e H) em folhas de genótipos de feijão Vigna sob estresse de 24 horas e reidratação com as lâminas de irrigação.

Apesar de algumas plantas terem tendência de reduzir o teor de clorofila sob condições de estresse hídrico, seja pela degradação e restrição da síntese da mesma (LIU et al., 2011; TAIZ; ZEIGER, 2013). Os teores de clorofila $a$ dos genótipos de feijão Vigna não foram influenciados pelo reidratação dos tecidos após estresse hídrico por 24 h, indicando que não houve síntese ou degradação da clorofila mesmo com exclusão do estresse a curto prazo. Assim pode inferir que efeito do estresse hídrico sobre os teor de clorofila do feijão Vigana ocorrem a longo prazo (aclimatação).

Desempenho semelhante ao observado na clorofila $a$ e $b$, foi verificado na concentração de carotenóides nas folhas dos genótipos de feijão Vigna. Os maiores teores desse pigmento foram encontrados com a menor reposição hídrica, com destaque para o genótipo 'BRS Marataoã' que obteve melhores valores de carotenóides chegando a ter variação de $100 \%$ entre os valores observados no genótipo de feijão 'BRS Aracé' (Figura 4A, B, C e D). Os carotenóides desempenham um papel importante na foto-proteção (MUNNÉBOSCH et al., 2007), onde seu aumento sob condições de déficit hídrico na planta indica uma maior necessidade de foto-proteção por carotenóides (ELSHEERY; CAO, 2008). Com isso, o aumento da síntese de carotenoides pode estar relacionado à inativação da enzima clorofilase responsável por degradar a clorofila, permitindo o seu acúmulo aumento com isso, mantendo atividade fotossintética dessas plantas, mesmo com área foliar reduzida pelo estresse hídrico. 
A

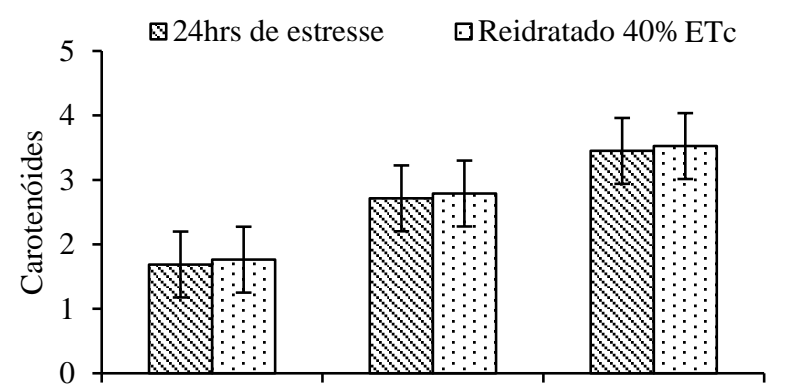

$\mathrm{C}$

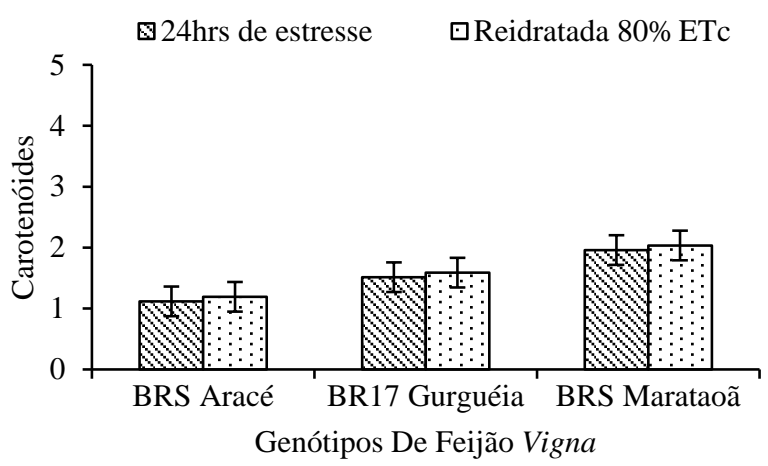

B

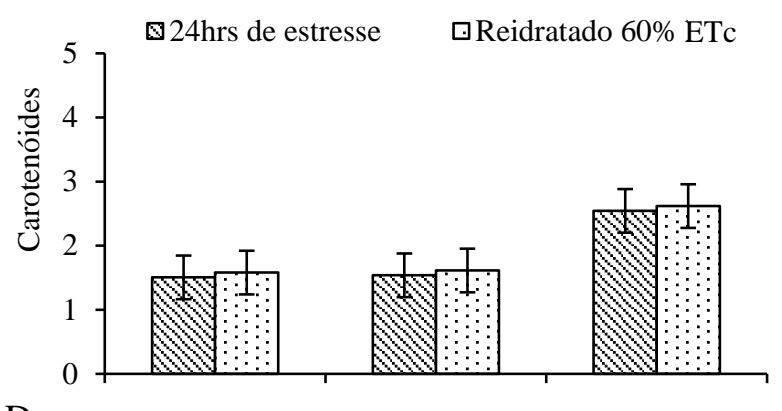

$\mathrm{D}$

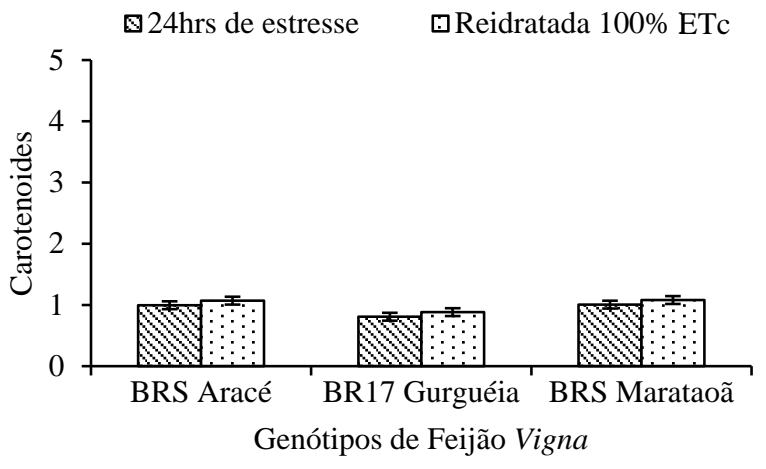

Figura 4. Concentração de carotenóides $\left(\mu \mathrm{g} \mathrm{g}^{-1}\right)$ em folhas de genótipos de feijão Vigna sob estresse de 24 horas e reidratação com as lâminas de irrigação.

\section{CONCLUSÕES}

A irrigação no feijão Vigna, para a região de estudo, pode ser programada em 80\% da evapotranspiração da cultura.

O genótipo 'BRS Marataoã' obteve o maior crescimento, acúmulo de massa seca e teores de pigmentos cloroplastídicos, destacando-se como mais tolerante ao estresse hídrico que o 'BRS Aracé' e o 'BR 17 Gurgueia’.

O genótipo 'BRS Aracé' obteve os piores índices de crescimento, acúmulo de massa seca e os menores teores de carotenoides sob condições de déficit hídrico, sendo o mais sensível entre os genótipos 'BRS Marataoã' e 'BR 17 Gurgueia'.

\section{REFERÊNCIAS BIBLIOGRÁFICAS}

BASTOS, E. A.; RAMOS, H. M. M.; ANDRADE JÚNIOR, A. S.; NASCIMENTO, F. N.; CARDOSO, J. M. Parâmetros fisiológicos e produtividade de grãos verdes do feijão-caupi sob déficit hídrico. Water Resources and
Irrigation Management, v. 1, n.1, p. 31-37, 2012.

BUCHANAN, B. B.; GRUISSEM, W.; JONES, R. L. Biochemistry and molecular biology of plants. Rockville: American Society of Plant Physiologists, 2000. 1408p.

CAVALCANTI, F. J. Recomendações de adubação para o Estado de Pernambuco. $2^{\mathrm{a}}$ Aproximação. Recife: Instituto Agronômico de Pernambuco - IPA, 2008. 212p. Il.

DUTRA, A. F.; MELO, A. S.; FILGUEIRAS, L. M. B.; SILVA, A. R. F.; OLIVEIRA, I. M.; BRITO, M. E. B. Parâmetros fisiológicos e componentes de produção de feijãocaupi cultivado sob deficiência hídrica. Revista Brasileira de Ciências Agrária, v. 10, n. $2, \quad$ p. $189-197,2015$. 10.5039/agraria.v10i2a3912

ELSHEERY, N.; CAO, K. F. Gas exchange, chlorophyll fluorescence, and osmotic adjustment in two mango cultivars under drought stress. Acta Physiologiae Plantarum, 
v. 30, n. 6, p. 769-777, 2008. http://dx.doi.org/10.1007/s11738-008-0179-x.

FERRAZ, R. L. S.; MELO, A. S.; SUASSUNA, J. F.; BRITO, M. E. B.; FERNANDES, P. D.; NUNES JÚNIOR, E. S. Trocas gasosas e eficiência fotossintética em ecótipos de feijoeiro cultivados no semiárido. Revista Ciência Agronômica, v. 42, n. 4, p. 957-964, 2011. http://dx.doi.org/10.1590/S1983-

40632012000200010.

FIGUEIREDO, M. G.; FRIZZONE, J. A.; PITELLI, M. M; REZENDE, R. Lâmina ótima de irrigação do feijoeiro, com restrição de água, em função do nível de aversão ao risco do produto. Acta Scientiarum. Agronomy, v. 30, n. $1, \quad$ p. $81-87, \quad 2008$. http://dx.doi.org/10.4025/actasciagron.v30i1.11 35.

IBGE. Instituto Brasileiro de Geografia e Estatística. Produção agrícola nacional. Brasília, julho, 2013. Capturado em 9set. 2013. Online. Disponível na Internet http://www.ibge.gov.br/home/.

LARCHER, W. Ecofisiologia Vegetal. Tradução: PRADO, C. H. B. A.; Franco. A. C. São Carlos: Rima, 2000. 533p.

LICHTENTHALER, H.K. Chlorophylls and carotenoids: pigments of photosynthetic biomembranes. Methods in Enzymology, v. 148, n. 2, p. 350-382, 1987. https://doi.org/10.1016/0076-6879(87)48036-1.

LIU, C.; GUO, J.; CUI, Y.; LÜ, T.; ZHANG, X.; SHI, G. Effects of cadmium and salicylic acid on growth, spectral reflectance and photosynthesis of castor bean seedlings. Plant and Soil, v. 344, n. 1, p. 131-141, 2011. http://dx.doi.org/10.1007/s11104-011-0733-y.

MOREIRA, R. C. L.; BRITO, M. E. B.; QUEIROGA, R. C. F.; FRADE, L. J. G.; COSTA, F. B.; PEREIRA, F. H. F.; SILVA, L. A.; OLIVEIRA, C. J. A. Gas exchange, growth and yield of cowpea genotypes under different irrigation strategies. African Journal of
Agricultural Research, v. 11, n. 26, p. 22862294, 2016. http://dx.doi.org/10.5897/AJAR2016.11221.

MOUSINHO, F. E. P.; ANDRADE JR, A. S.; FRIZZONE, J. A. Viabilidade econômica do cultivo irrigado do feijão-caupi no Estado do Piauí. Acta Scientiarum Agronomy, v. 30, n. 1, p. 139-145, 2008. http://dx.doi.org/10.4025/actasciagron.v30i1.11 65.

MUNNÉ-BOSCH, S.; PEÑUELAS, J.; LLUSIA, J. A deficiency in salicylic acid alters isoprenoid accumulation in water-stressed nahg transgenic Arabidopsis plants. Plant Science, v. 172, n. 4, p. 756-762, 2007. https://doi.org/10.1016/j.plantsci.2006.12.005.

MUÑOZ-PEREA, C. G.; TERÁN, H.; ALLEN, R. G.; WRIGHT, J. L.; WESTERMANN, D. T.; SINGH, S. P. Selection for drought resistance in dry bean landraces and cultivars. Crop Science, v. 46, n. 9, p. 2111-2120, 2006. http://dx.doi.org/10.2135/cropsci2006.01.0029.

NASCIMENTO, S. P. N.; BASTOS, E. A.; ARAUJO, E. C. E.; FILHO, F. R. F.; SILVA, E. $M$. Tolerância ao deficit hídrico em genótipos de feijão-caupi. Revista Brasileira de Engenharia Agrícola e Ambiental, v. 15, n. 8, p. 853-860, 2011. http://dx.doi.org/10.1590/S141543662011000800013.

NEPOMUCENO, A. L.; NEUMAIER, N.; FARIAS, J. R. B.; OYA, T. Tolerância à seca em plantas: Mecanismos fisiológicos e moleculares. Revista Biotecnologia, Ciência \& Desenvolvimento, v. 4, n. 23, p. 12-18, 2001.

ONOFRE, A. V. C. Diversidade genética e avaliação de genótipos de feijão Vigna contrastantes para resistência aos estresses bióticos e abióticos com marcadores SSR, DAF e ISSR. 2008. 76 p. Dissertação (Mestrado em Ciências Biológicas) - Universidade Federal de Pernambuco, Recife.

PAVANI, L. C.; LOPES, A. S.; PEREIRA, G. T. Desenvolvimento da cultura do feijoeiro 
submetida a dois sistemas de manejo de irrigação e de cultivo. Acta Scientiarum Agronomy, v. 31, n. 3, p. 453-459, 2009. http://dx.doi.org/10.4025/actasciagron.v31i3.62 1.

QUEIROGA, J. L.; ROMANO, E. D. U.; SOUZA, J. R. P.; MIGLIORANZA, E. Estimativa da área foliar do feijãovagem (Phaseolus vulgaris L.) por meio da largura máxima do folíolo central. Horticultura Brasileira, v. 21, n. 1 , p. 2003. http://dx.doi.org/10.1590/S010205362003000100013.

RIBEIRO, R. V.; SANTOS, M. G.; SOUZA, G. M.; MACHADO, E. C.; OLIVEIRA R. F.; ANGELOCCI, L. R.; PIMENTEL, C. Environmental effects on photosynthetic capacity of bean genotypes. Pesquisa Agropecuária Brasileira, v. 39, n. 9, p. 615-
623, 2004. http://dx.doi.org/10.1590/S0100$204 X 2004000700001$.

SANTOS, H. G.; JACOMINE, P. K. T.; ANJOS, L. H. C.; OLIVEIRA, V. A.; OLIVEIRA, J. B.; COELHO, M. R.; LUMBRERAS, J. F.; CUNHA, T. H. J. F. Sistema brasileiro de classificação de solos. 3.ed. Brasília: Editora Embrapa, 2013. 353p.

SOUZA, T. M. A.; SOUZA, T. A.; LAUTER SILVA SOLTO; SÁ, F. V. S.; PAIVA, E. P. de; BRITO, M. E. B.; MESQUITA, E. F. Crescimento e trocas gasosas do feijão caupi cv. brs pujante sob níveis de água disponível no solo e cobertura morta. Irriga, v. 21, n. 4, p. 796-805, 2016.

http://dx.doi.org/10.15809/irriga.2016v21n4p7 96-805.

TAIZ, L.; ZEIGER, E. Fisiologia vegetal. 5.ed. Porto Alegre: Artmed, 2013. 918p. 